\title{
Investigations on small-scaled welded structures of austenitic stainless steel
}

\author{
U. Reisgen, K. Willms, J. Schäfer*, M. Türker, J. Hegger, M. Classen, M. Feldmann, M. Kopp
}

ISF-Welding and Joining Institute, RWTH Aachen University, Pontstraße 49, 52062 Aachen, Germany

Received 2 June 2015, received in revised form 24 May 2019, accepted 28 June 2019

\begin{abstract}
The present study describes the process characteristics of the Cold-Metal-Transfer (CMT) Pin-Welding by welding structures on austenitic stainless steel (AISI 304) and characterizes the corresponding mechanical properties. Pin-Welding technology enables the possibility of welding small-scaled structures out of the welding wire. The mechanical properties and microstructures of the welded structures were investigated on different pin formations. Experimental samples extracted from the welded structure were subjected to tensile and hardness tests and microstructural examinations. Tensile test results were obtained lower than the welding wire owing to the process heat input, but both presented similar proportional results. The structures hardness formed out of wire diameter of $0.8 \mathrm{~mm}$ and $1.2 \mathrm{~mm}$ was obtained in an interval between 200-250 HV. Because the base metal has nearly similar hardness values, the whole structure exhibits a stable hardness distribution after the welding process.
\end{abstract}

K e y w o r d s: welding, joining, austenitic steels, stainless steels, mechanical properties

\section{Introduction}

Austenitic stainless steels are extensively used in many fields of manufacturing because of their superior mechanical and functional properties such as high ductility, high strength, acceptable weldability and superb resistance against corrosion [1-8]. Additionally, they have an exceptional toughness and a high heat resistance, wherefore they can successfully be used from cryogenic to red-hot temperatures [9]. They can be made soft enough (i.e., with a yield strength about $200 \mathrm{MPa}$ ) to be easily formed by the same tools that work with carbon steel, but they can also be made incredibly strong by cold work up to yield strength of over $2000 \mathrm{MPa}[10]$.

Type 304 of austenitic stainless steel family, which is broadly used in industrial applications (i.e., automotive, pressure vessels, paper industry, chemical and food processing industries) has excellent mechanical properties and strong corrosion resistance. Properties like ductility and toughness of this steel are better in comparison to other steels. However, as the thermal conductivity of austenitic stainless steel is limited, excess heat input leads to coarse grains [11]. Elements like chromium, nickel, silicon, nitrogen, copper, titanium, niobium and molybdenum are added to provide corrosion protection. A combination of manganese with sulfur and phosphorus improves the machinability and weldability [12].

Almost all types of stainless steels can be welded with gas-metal-arc welding [13]. A Pin-Welding process is a special form of CMT-Welding, which is a gasshielded welding process based on short arc welding. This technology was enhanced over the last years to further reduce the heat input into the base material. Particularly, with regard to welding thin sheet metals or root passes, a high energy input causes thermal distortion and thereby influences the joint geometry and the gap width of the joining task.

Those disadvantages can be widely avoided by using digitally controlled short arc processes, which yield the same deposition rate while reducing the heat input. The CMT technology meets those demands by making use of a mechanical resolution of a short circuit combined with an additional reduction of energy during the short circuit phase. This is realized by a highly dynamic servo-motor, which pulls the wire out of the weld pool in the case of detecting a voltage

*Corresponding author: tel.: +49 241/80-93870; fax: +49 241/80-92170; e-mail address: office@isf.rwth-aachen.de 
Table 1. Chemical composition and mechanical properties of the base material (wt.\%)

\begin{tabular}{|c|c|c|c|c|c|c|c|c|}
\hline $\mathrm{C}$ & $\mathrm{Si}$ & $\mathrm{Mn}$ & $\mathrm{Ni}$ & $\mathrm{Cr}$ & Mo & $\mathrm{N}$ & S & $\mathrm{P}$ \\
\hline 0.021 & 0.41 & 1.56 & 8.03 & 18.15 & 0.28 & 0.074 & 0.002 & 0.03 \\
\hline \multicolumn{2}{|c|}{$\begin{array}{l}\text { Yield strength, } R_{\mathrm{p}} 0.2 \% \\
\quad(\mathrm{MPa})\end{array}$} & \multicolumn{3}{|c|}{$\begin{array}{l}\text { Ultimate tensile strength } \\
\qquad(\mathrm{MPa})\end{array}$} & \multicolumn{2}{|c|}{$\begin{array}{c}\text { Strain at fracture } \\
(\%)\end{array}$} & \multicolumn{2}{|c|}{ Hardness, HV } \\
\hline \multicolumn{2}{|c|}{320} & \multicolumn{3}{|c|}{655} & \multicolumn{2}{|c|}{48} & \multicolumn{2}{|c|}{184} \\
\hline
\end{tabular}

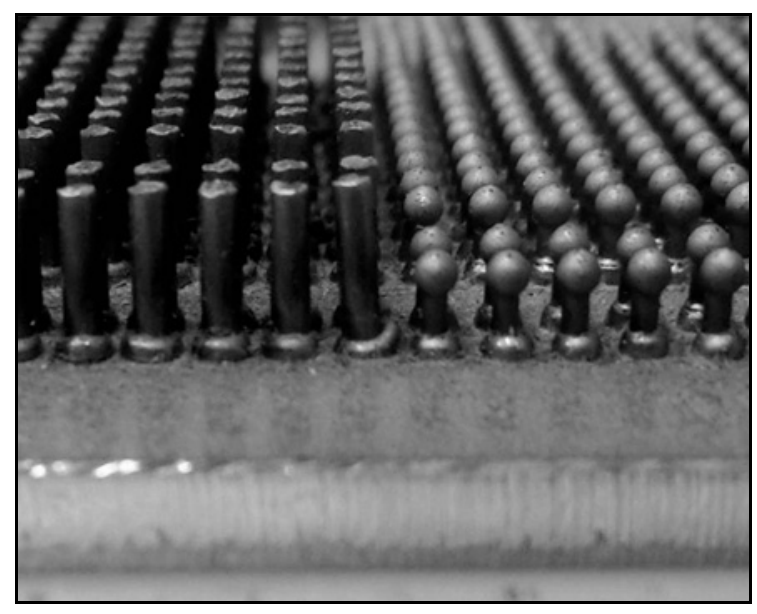

Fig. 1. Welded pikes (left) and pins (right).

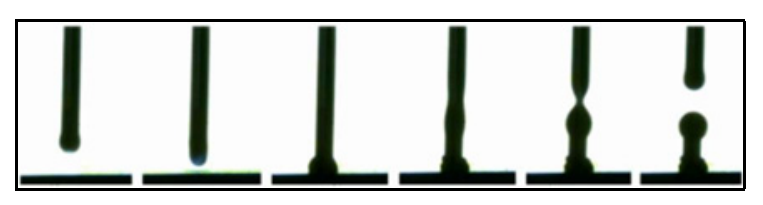

Fig. 2. High-speed-sections of a welded pin.

drop within the short circuit [14]. The CMT process is a modified metal inert gas welding process based on a short arc process, which is characterized by low heat input and a low or rather no-spatter occurrence $[15,16]$. Therefore, this technology is used for many welding applications in the area of thin sheet welding and brazing [17].

In the course of this development, it was found out that the combination of current feed and wire movement provides the possibility of welding small-scaled structures (Fig. 1).

For the first time, small-scaled "pikes" (Fig. 1 left) and "pins" (Fig. 1 right) can be formed out of the welding wire by being welded on the base material within one step. Through a first pulse and a corresponding wire movement, the wire is welded with a first arc onto the base material. By the following current and coordinated reverse motion of the wire, it is cut off (Fig. 2). One option of the process generates structures with spherical heads by melting the wire in a second pulse with a ball forming due to surface tensions of the liquid wire end. Those pin structures can be used as form-fitting elements for the combination with various other materials like i.e. concrete.

The current research state of this technology grants several pin geometry variations up to a height of $5 \mathrm{~mm}$.

At present works, pins with spherical heads are used as form-fit elements for applications in a combination of steel with carbon fibre laminate and textiles [18-21].

A completely new approach is the combination with concrete, especially in the area of civil engineering, where costs and materials can be saved by lightweight construction. Such a new combination method enables material combinations with elements smaller than the smallest shear stud.

\section{Material and experimental procedures}

The investigations were carried out on austenitic stainless steel (AISI 304) by a metal thickness of $3 \mathrm{~mm}$ (Table 1), which has the advantage of corrosion resistance and is, therefore, useful for civil engineering applications in free environmental use.

For the investigations, one welding wire of two different diameters (ER308LSi $0.8 \mathrm{~mm}, 1.2 \mathrm{~mm}$ ) was used, which is stainless, resistant to intercrystalline and wet corrosion up to $350^{\circ} \mathrm{C}$. The resistance against corrosion of this solid wire is due to the high content of chrome and nickel, which is in a slight overbalance in contrast to the base material. The welding details and the chemical composition of the solid wire are given in Tables 2, 3. For all experiments, the pin structures were welded on sheets of $3 \mathrm{~mm}$ thickness, in which preheating was neglected. As a shielding gas, a mixture of $97.5 \%$ argon and $2.5 \%$ carbon dioxide was used due to the welding process and the choice of high-alloyed steel.

For the structural investigation, individual pin samples (Fig. 3) were taken out of a welded pin structure, and the microstructure of that pin was considered in detail.

Furthermore, tensile test specimens were extracted separately from the welded structures. The test appli- 
Table 2. CMT-Pin welding details

\begin{tabular}{cccccc}
\hline Weld joint & Welding position & Type of consumable & Protection & Plate thickness & Preheat temp. $\left({ }^{\circ} \mathrm{C}\right)$ \\
\hline $\mathrm{PW}-1$ & $\mathrm{PA}$ & ER308LSi $(0.8 \mathrm{~mm})$ & $97.5 \% \mathrm{Ar}+2.5 \% \mathrm{CO}_{2}$ & $3 \mathrm{~mm}$ & None \\
$\mathrm{PW}-2$ & $\mathrm{PA}$ & ER308LSi $(1.2 \mathrm{~mm})$ & $97.5 \% \mathrm{Ar}+2.5 \% \mathrm{CO}_{2}$ & $3 \mathrm{~mm}$ & None \\
\hline
\end{tabular}

Table 3. Welding wire specified composition values

\begin{tabular}{cccccc}
\hline Elements & $\mathrm{C}$ & $\mathrm{Si}$ & $\mathrm{Mn}$ & $\mathrm{Cr}$ & $\mathrm{Ni}$ \\
\hline ER308LSi $(0.8 \mathrm{~mm} / 1.2 \mathrm{~mm})$ & 0.02 & 0.9 & 1.7 & 20.0 & 10.0 \\
\hline
\end{tabular}

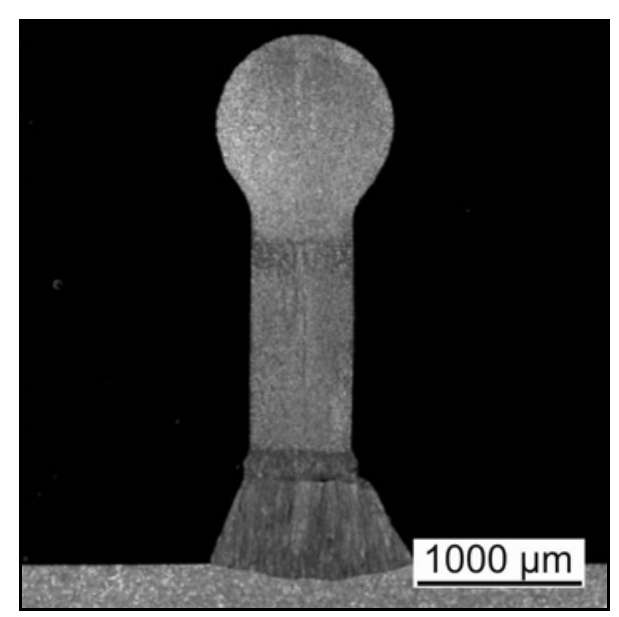

Fig. 3. Macrostructure of one pin (wire diameter $0.8 \mathrm{~mm}$ ).

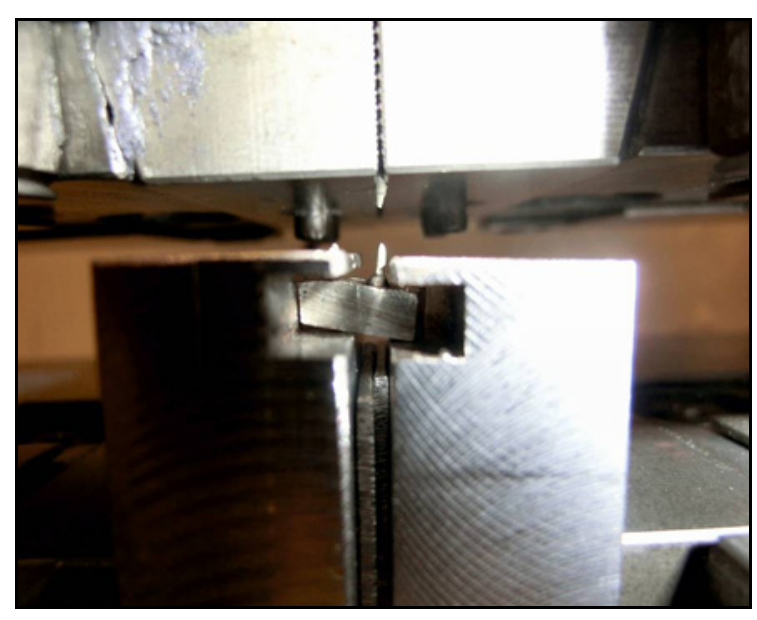

Fig. 4. Tensile test setting.

cation for those was made by clamping the pinball in the top and embedding the described cut of the base material in a notch (Fig. 4).

As an additional observing method, Vickers hardness measurements (DIN EN ISO 6507-1) were carried

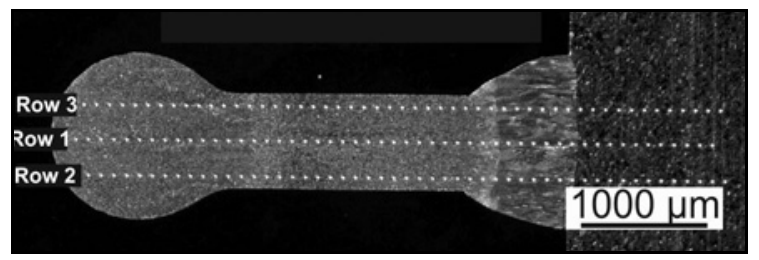

Fig. 5. Microhardness test.

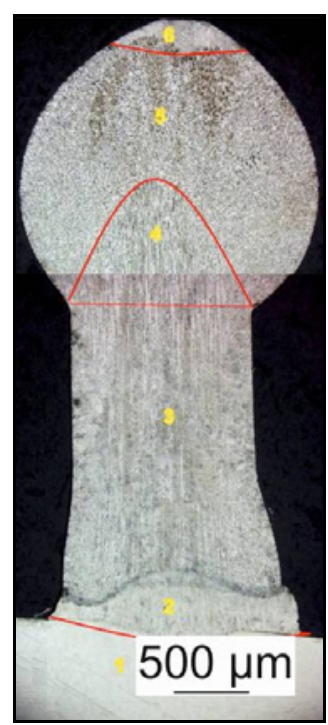

Fig. 6. Classification of different zones in a welded pin.

out under a load of $0.985 \mathrm{~N}$ over cross sections on three elongated lines (Fig. 5).

\section{Results and discussion}

In the resulting experiments, the pin structure is categorized in six different zones (Fig. 6), which are equivalent for each pin.

Zone No. 1:

As shown in Fig. 7, this zone represents unaffected 


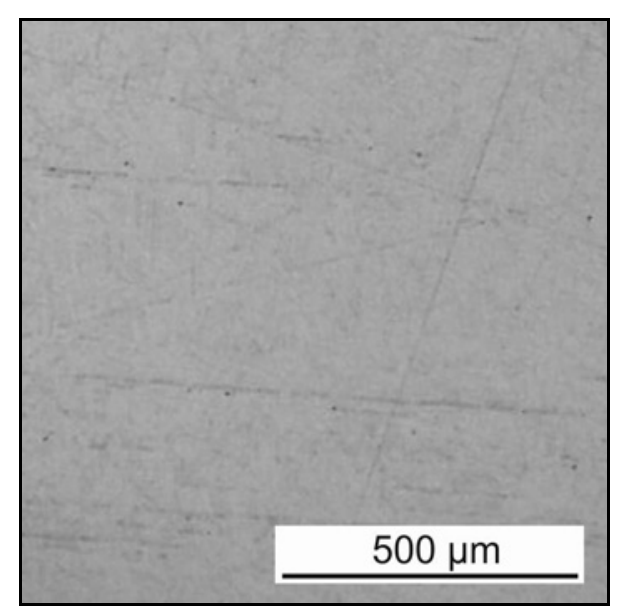

Fig. 7. Unaffected zone in the base material.
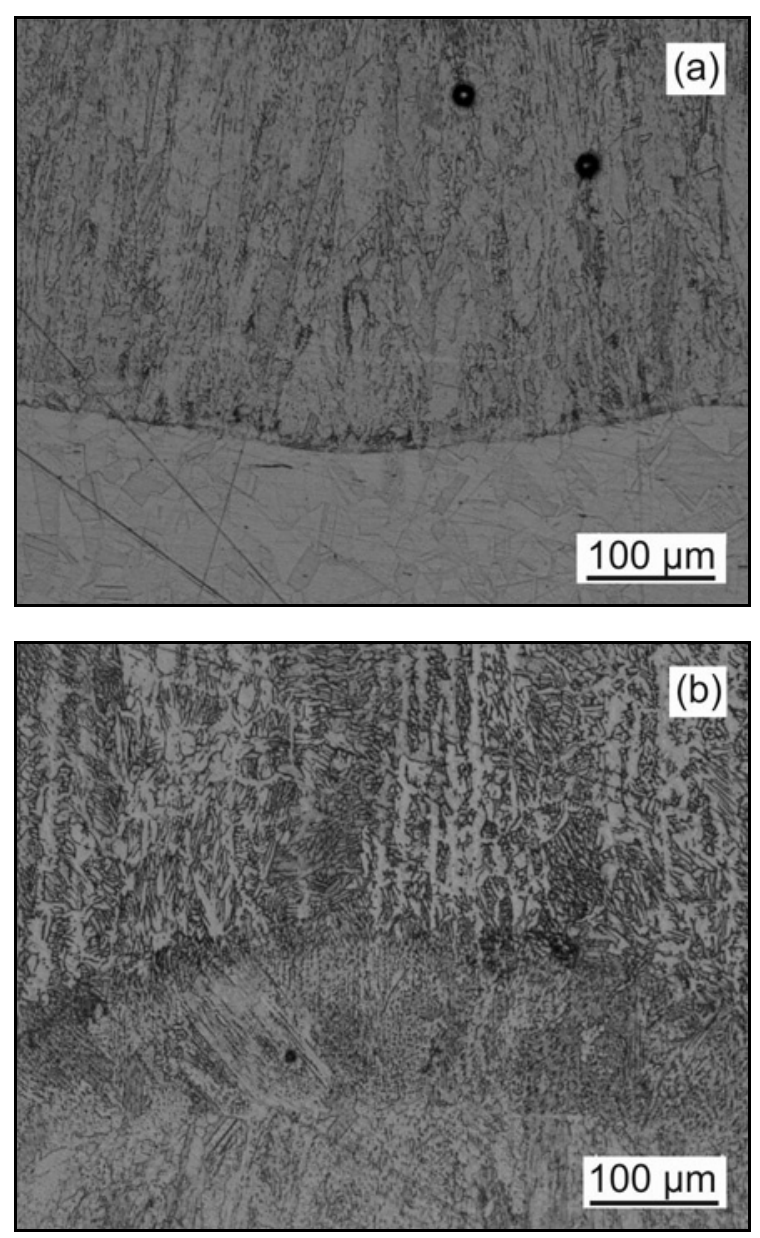

Fig. 8. Zone No. 2: base material (a) and wire material (b).

base material of AISI 304. A slight part of the heat affected-zone caused by the molten metal is assigned to the subsequent zone. Due to a less heat input of the

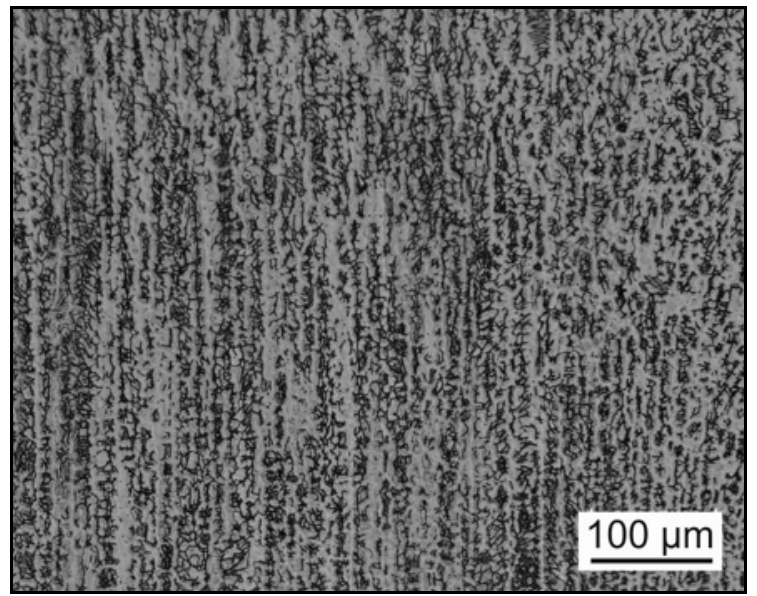

Fig. 9. Microstructure out of the middle pin shaft.

CMT process and the short time of the burning first arc, the heat affected-zone is of a minimal shape.

\section{Zone No. 2:}

While the base material in zone No. 1 was nearly unaffected, zone No. 2 depicts the solidified molten metal of the wire produced by the first arc of the CMT-Pin process. Besides the molten metal, two different heat affected-zones in a small characteristic shape can be developed in the base material (Fig. 8a) and wire material (Fig. 8b).

\section{Zone No. 3:}

This zone is declared as "pin shaft". The pin shaft is nearly unaffected after the forming of the heat affected zone between the weld and wire material. After welding the base, the arc of the CMT process distinguishes, so that no change of the microstructure in the pin shaft is given. Just the longitudinal structure of the wire extraction can be observed (Fig. 9).

\section{Zone No. 4:}

This zone consists of a heat affected-zone between the unaffected pin shaft and the surrounding ball, which is built out of a liquid drop by a second current input of the CMT-Pin process. In comparison to the first arc, which is forming the base, the second current stays for a longer holding time and therefore induces a higher heat input. This resistance heating constricts the wire and a second arc forms a liquid drop of liquid weld metal after the current has narrowed the wire by resistance warming. During the forming of the ball, an irregular cooling begins as well as heterogeneous nucleation. This nucleation is in the response of the formation and growth of an occurring grain structure in the rest of the ball, while the structure of the pin shaft stays in the transition zone within the ball unaffected due to a less heat input (Fig. 10).

\section{Zone No. 5:}

This zone represents the ball of the pin (Fig. 11). It can be described as a spherulitic body with a fine 


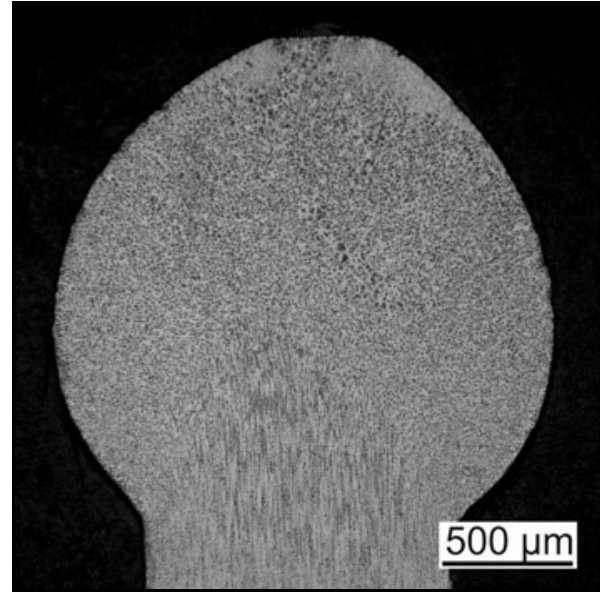

Fig. 10. Zone No. 4.

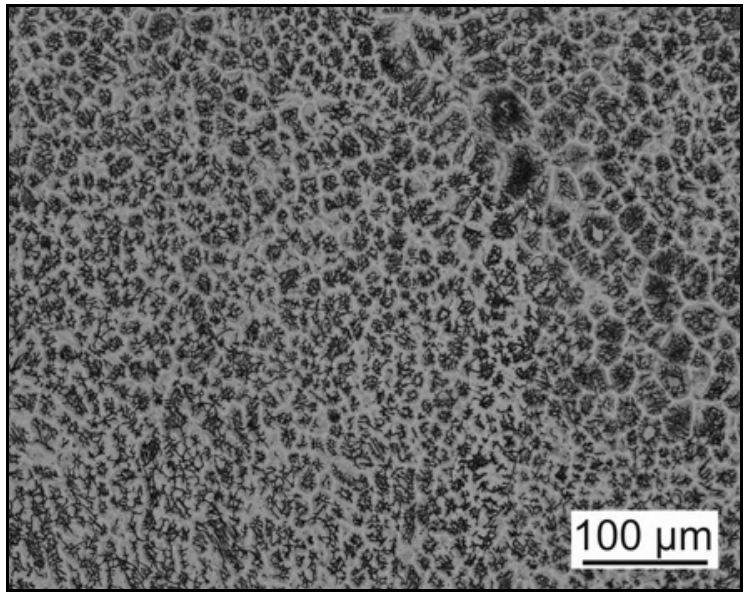

Fig. 11. Structure in the ball.

globular structure. Between zones no. 4 and 5, a transcrystalline area can be observed. After pulling of the welding wire, the last arc occurs. This arc causes the detachment of the remaining wire material. Hence the pinball drops in a liquid condition under gravity and solidifies directly. Owing to the precooling of the pin shaft, the molten structure is formed by surface stresses.

\section{Zone No. 6:}

At the top of the pinball, the heat concentrates in the middle of the ball and causes bigger grains (Fig. 12), while the surrounding areas become cooler. At this part, the stay of a higher temperature causes further growth in the middle of the ball. These causes bring out the forming of coarse grains.

In further experiments, tensile tests were done. Tensile tests aim to predict the elastic and plastic behavior of materials under static load. Due to that cause, it was important to obtain tensile test results

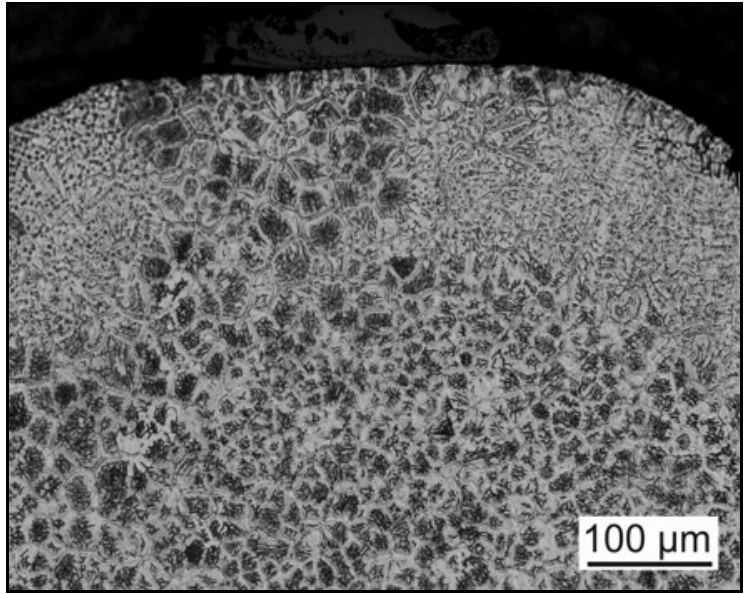

Fig. 12. Zone No. 6.
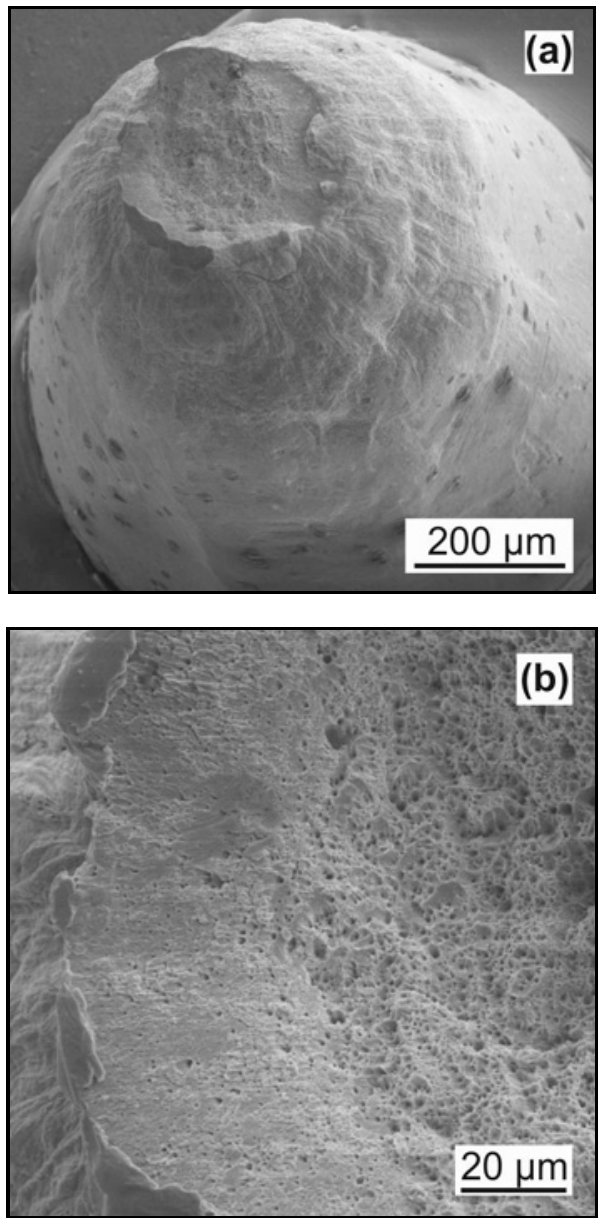

Fig. 13. SEM images of fracture surface in the tensile test specimen.

from the way of using it in pin applications. All researched parts were broken in the middle of the pin shaft, where no influence in the structure was obtained 


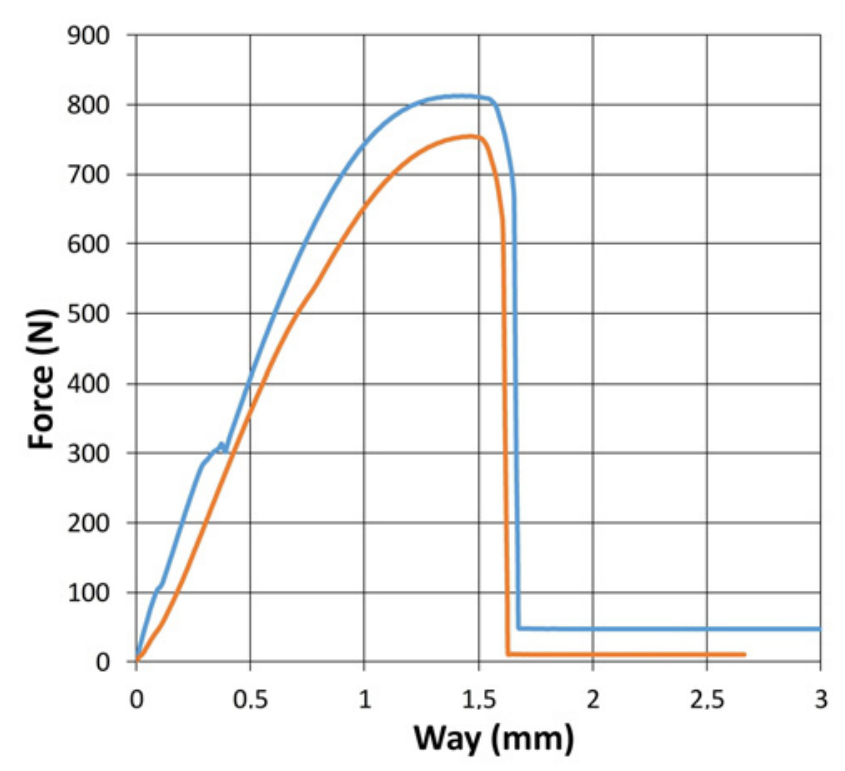

Fig. 14. Tensile test of wire with diameter $0.8 \mathrm{~mm}$.

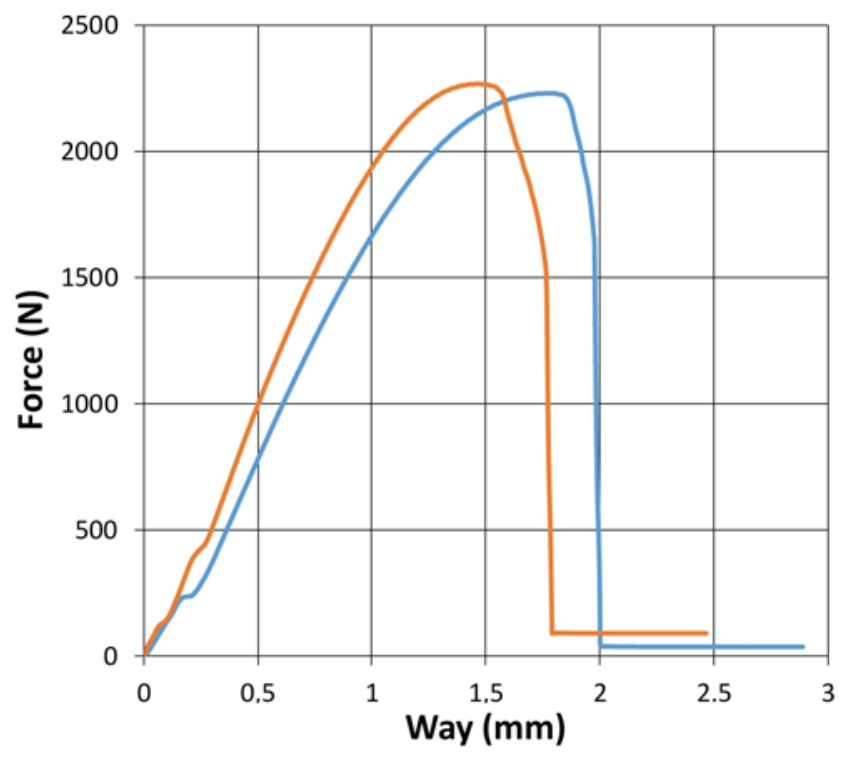

Fig. 15. Tensile test of wire with diameter $1.2 \mathrm{~mm}$.

before. The samples did not exhibit a clear yield point.

In all experiments, a cup-and-cone fracture occurred (Fig. 13), which presents the formability of the pin structure. In SEM investigations, a clear reduction of the diameter area by necking can be observed with the fracture surface and also fracture lips between them (Fig. 13a). In Fig. 13b, the fracture lips are obvious in higher magnification in contrast to the center field, which fractured as a brittle cleavage type after the necking. The experiments present a transgranular fracture in the deformation zone and an intergranular fracture in the brittle zone.

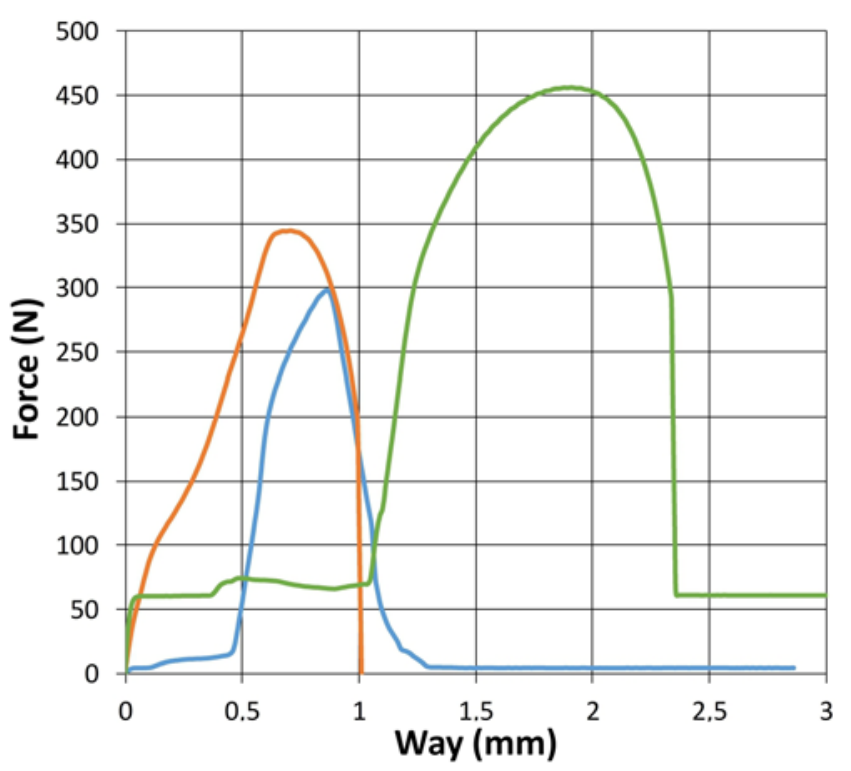

Fig. 16. Pin tensile test out of wire with diameter $0.8 \mathrm{~mm}$.

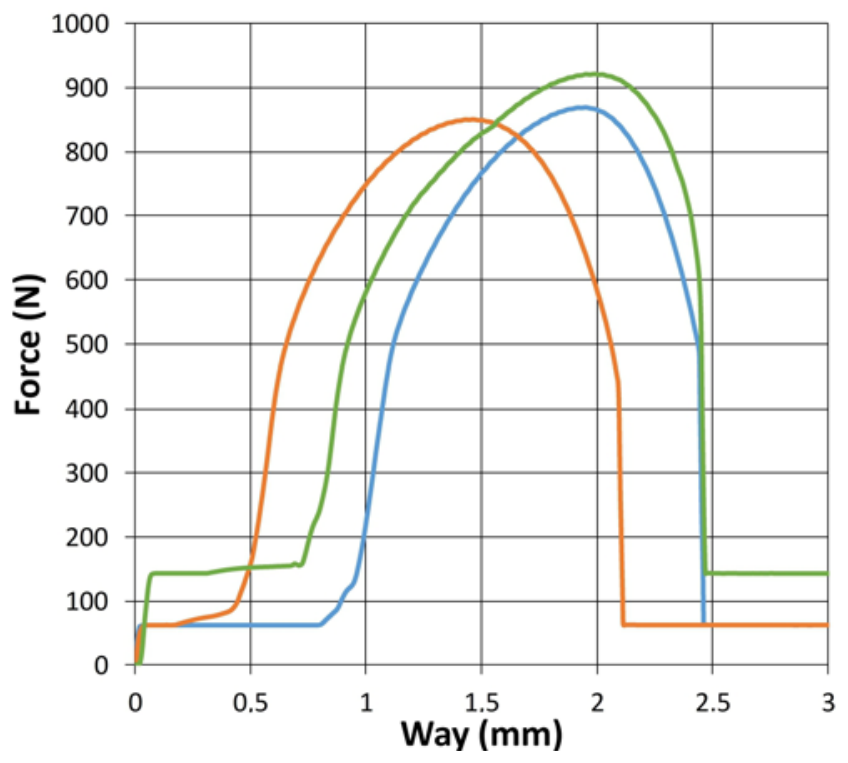

Fig. 17. Pin tensile test out of wire with diameter $1.2 \mathrm{~mm}$.

The ductile fracture occurred in all samples (Fig. 13), which presents the formability of the pin structure. Comparing with results just of the wire by using wire diameters of 0.8 and $1.2 \mathrm{~mm}$ (Figs. 14, 15), measurements of welded pins (Figs. 16, 17) were obtained in lower achievements due to the heat input during the welding process. However, both had similar proportional results.

According to hardness measurements, the results of the pin shaft and pinball are similar to each other (approximately $200 \mathrm{HV}$ ). The other zones' hardness formed out different results owing to the heat input. 

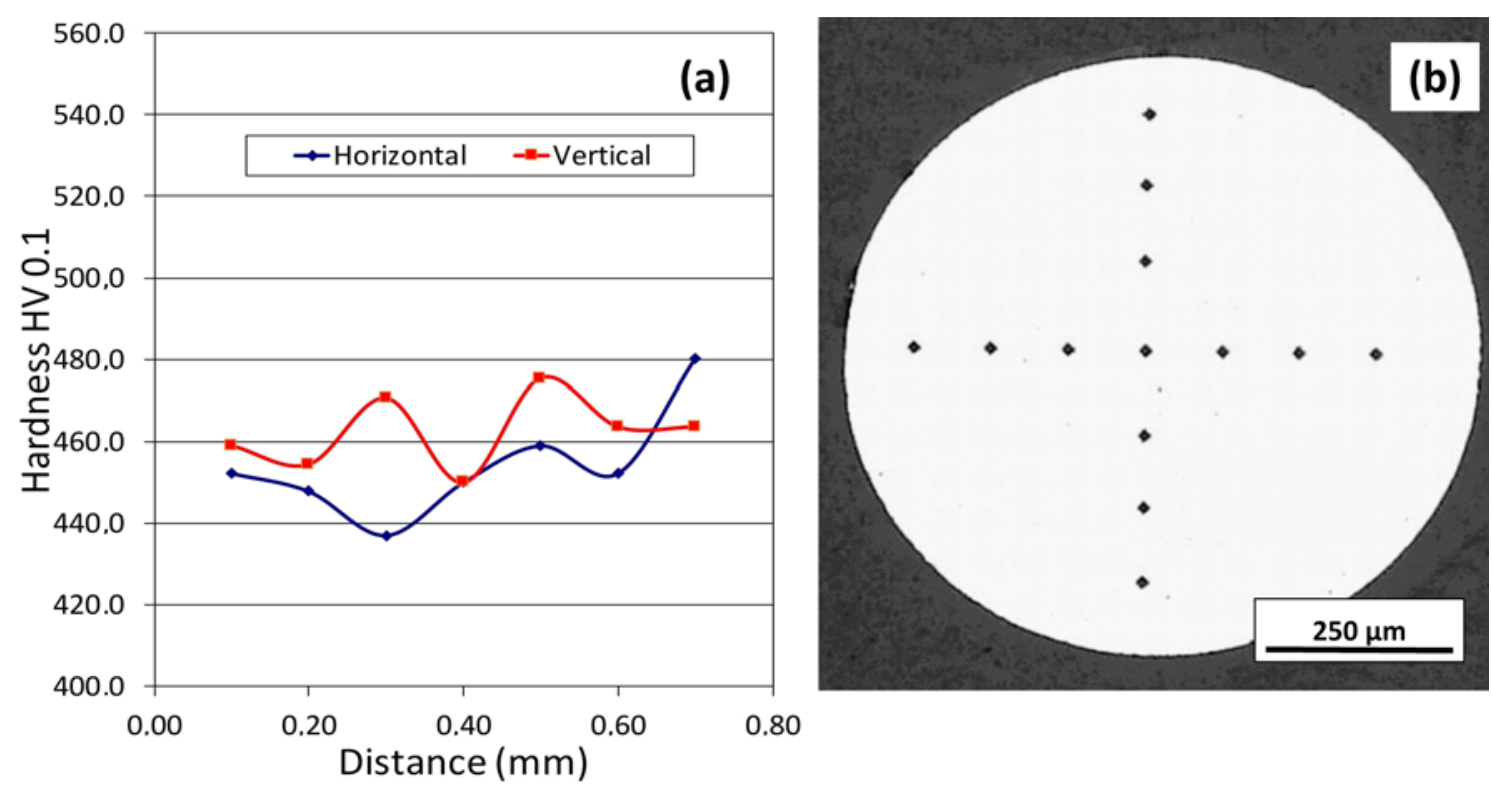

Fig. 18. Hardness measurement wire (diameter $0.8 \mathrm{~mm}$ ).
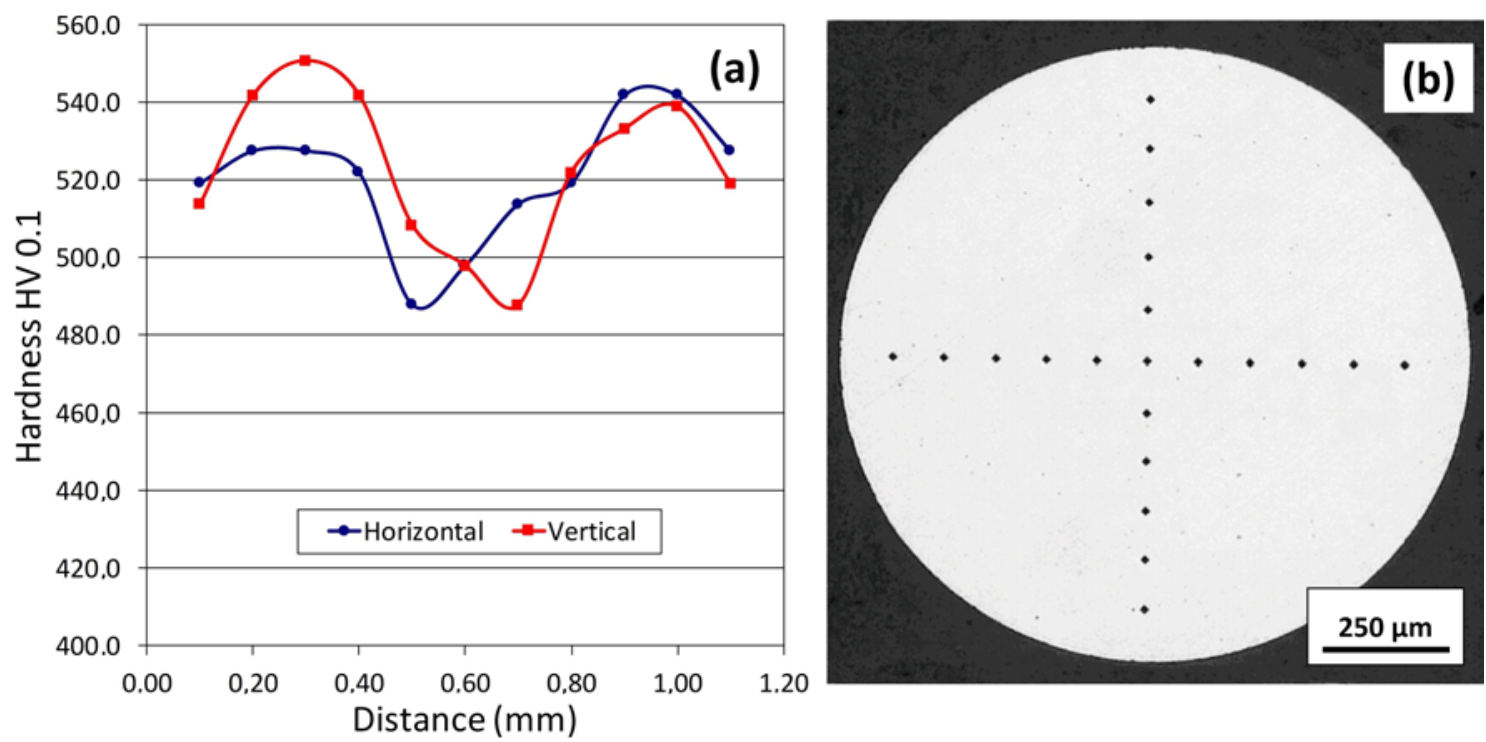

Fig. 19. Hardness measurement wire (diameter $1.2 \mathrm{~mm}$ ).

Considering the welding wire microhardness results (440-480 HV), as shown in Figs. 18, 19, the pin structures $(0.8$ and $1.2 \mathrm{~mm})$ show a hardness in an interval of $180-250 \mathrm{HV}$ (Figs. 20, 21), which is satisfactory. Because the base material has similar hardness values, the whole structure presents a stable hardness after the welding process. This situation is determined to be important from the way of preserving/holding of plastic deformation.

\section{Conclusions}

The following conclusions of this study concern- ing CMT-Pin welded structures of AISI 304 austenitic stainless sheets of steel can be drawn:

1. By using one welding wire type of two different diameters by the CMT-Pin welding, different microstructures were formed due to variable heat input. In the fusing phase of the process, current and voltage are just used for a short time, while the energetic level in the cooling phase, in which the shaft is built, is zero. The forming of the ball takes in contrast to this place with a current for a longer remaining time, in which a greater thermal influence on the material is observed.

2. According to tensile tests, all samples formed out a ductile fracture in the middle of the pin shaft, 


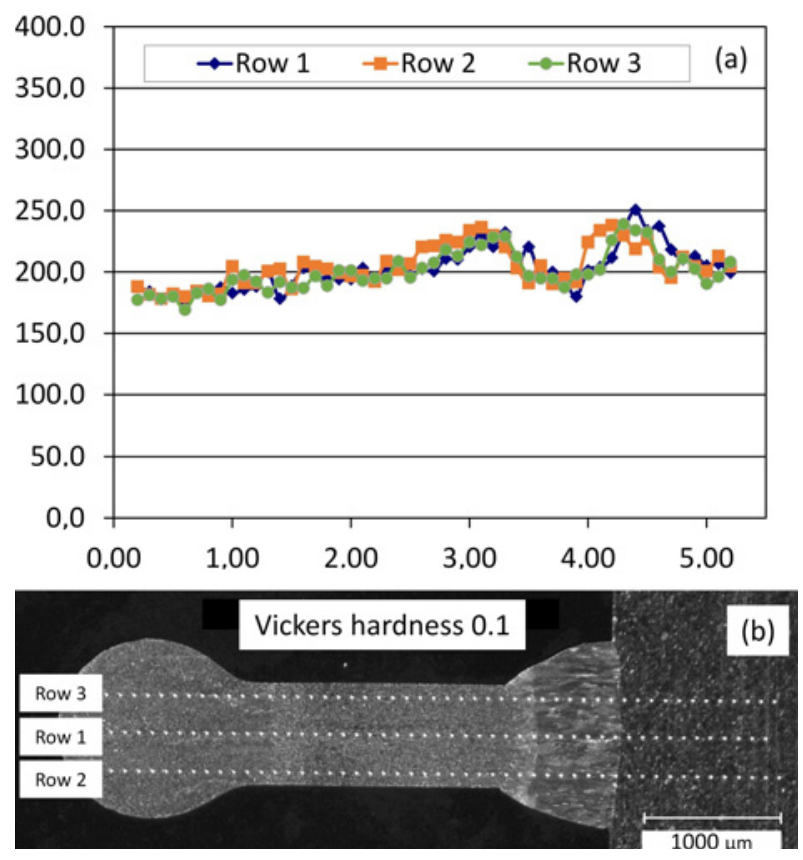

Fig. 20. Microhardness measurement pin/base material (wire diameter $0.8 \mathrm{~mm}$ ).

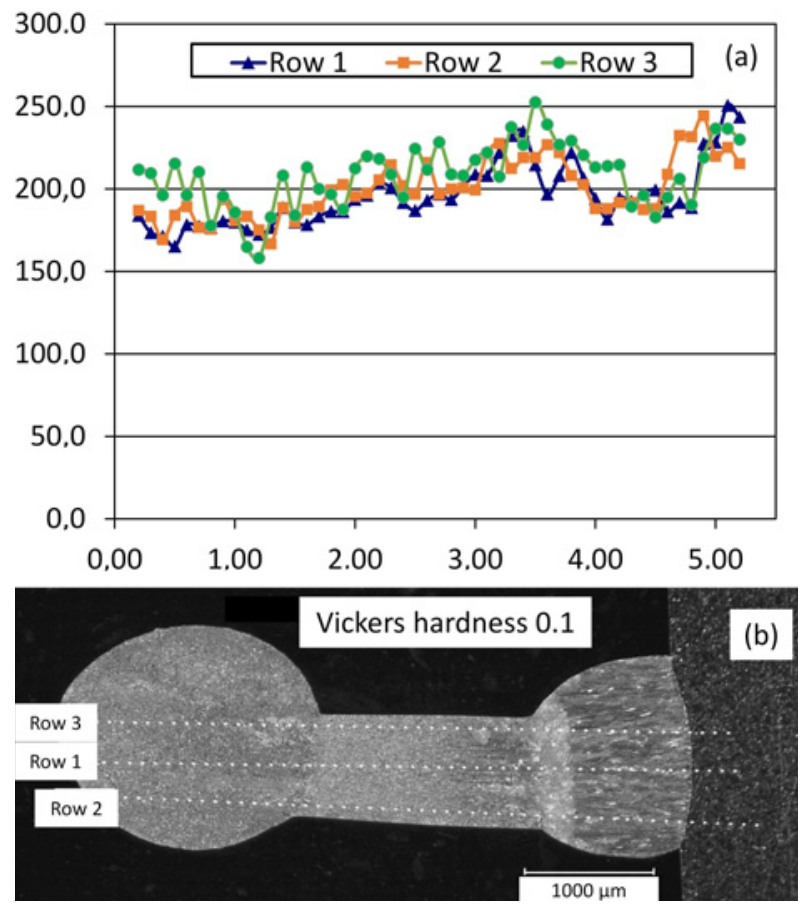

Fig. 21. Microhardness measurement pin/base material (wire diameter $1.2 \mathrm{~mm}$ ).

where the heat influence of the process is low, and no change of the microstructure was obtained before.

3 . The hardness of pins formed out of wire diameter of 0.8 and $1.2 \mathrm{~mm}$ was obtained in an interval between
200-250 HV. Because the base metal has nearly similar hardness values, the whole structure presents a stable hardness after the welding process.

\section{Acknowledgements}

This research work has been funded by the German Research Foundation (DFG) and is part of the research project RE 2755/32-1 "Untersuchung der Tragmechanismen neuartiger, kleinskaliger Pin-Verbundmittel zwischen Stahl und Beton". The researchers are very thankful for the support. The authors also would like to thank Fronius International GmbH for using the CMT-Pin-WeldingProcess.

\section{References}

[1] De Tiedra, P., Martin, O., Lopez, M., San-Juan, M.: Corrosion Science, 53, 2011, p. 1563.

doi:10.1016/i.corsci.2011.01.036

[2] Kujanpää, V.: Physics Procedia, 56, 2014, p. 630. doi:10.1016/j.phpro.2014.08.056

[3] Lyon, K. N., Marrow, T. J., Lyon, S. B.: Journal of Materials Processing Technology, 218, 2015, p. 32. doi:10.1016/i.jmatprotec.2014.11.038

[4] Yawas, D. S., Aku, S. Y., Aluko, S. O.: Results in Physics, 4, 2014, p. 127. doi:10.1016/i.rinp.2014.03.005

[5] Elsariti, S. M., Haftirman: Procedia Engineering, 53, 2013, p. 650. doi:10.1016/i.proeng.2013.02.084

[6] Chagasa, G. M. P., Barbosa, P. A., Barbosa, C. A., Machado, I. F.: Procedia CIRP, 8, 2013, p. 293. doi:10.1016/j.procir.2013.06.105

[7] Gupta, A. K., Krishnamurthy, H. N., Puranik, P., Singh, S. K., Balu, A.: Journal of Materials Research and Technology, 3, 2014, p. 370.

doi:10.1016/i.jmrt.2014.08.001

[8] Prasad, K. S., Rao, C. S., Rao, D. N.: Procedia Engineering, 97, 2014, p. 752. doi:10.1016/j.proeng.2014.12.305

[9] Ishimaru, E., Hamasaki, H., Yoshida, F.: Procedia Engineering, 81, 2014, p. 921. doi:10.1016/j.proeng.2014.10.118

[10] McGuire, M. F.: Stainless Steels for Design Engineers. Materials Park, ASM International 2008.

[11] Shilun, Z., Xiong, Z., Gang, Z.: Procedia Engineering, 24, 2011, p. 840. doi:10.1016/j.proeng.2011.11.2747

[12] Lippold, J. C., Kotecki, D. J.: Welding Metallurgy and Weldability of Stainless Steels. Hoboken, Wiley 2005.

[13] Tülbentci, K.: MIG/MAG Welding. Istanbul, Arctech 1998.

[14] Fronius International GmbH: Schweißpraxis Aktuell: CMT-Technologie-Cold Metal Transfer-ein neuer Metall-Schutzgas-Schweißprozess. Kissing, WEKA MEDIA GmbH \& Co. KG. 2013.

[15] Pickin, C. G., Williams, S. W., Lunt, M.: Journal of Materials Processing Technology, 211, 2011, p. 496. doi:10.1016/j.jmatprotec.2010.11.005

[16] Zhanga, H. T., Feng, J. C., He, P., Zhang, B. B., Chen, J. M., Wang, L.: Materials Science and Engineering A, 499, 2009, p. 111. doi:10.1016/j.msea.2007.11.124 
[17] Reisgen, U., Angerhausen, M., Geffers, C., Pipinikas, A.: In: Proceedings of 6th International Brazing and Soldering Conference. IBSC-2015. Florida, American Welding Society 2015.

[18] Stieglbauer, W., Kazmaier, J.: In: Proccedings of DVS-Congress 2009. Düsseldorf, DVS Media 2009, p. 100.

[19] Ucsnik, S., Scheerer, M., Zaremba, S., Pahr, D. H.: Composites: Part A,41, 2010, p. 369.
[20] Teufelberger GmbH, Kirth, R., Ebel, C.: Patent WO 2009/003207 A1, Anordnung zum Verbinden eines länglichen Elementes mit einer weiteren Komponente, 2009.

[21] Lotte, J., Reisgen, U., Schiebahn, A.: Journal of the Adhesion Society of Japan, Special Issue on WCARP-V, 51, 2015, S1, p. 264. 